\title{
Price discrimination through online couponing: Impact on likelihood of purchase and profitability
}

\author{
Mikhael Shor *, Richard L. Oliver \\ Owen Graduate School of Management, Vanderbilt University, 40121 st Avenue South, \\ Nashville, TN 37203, United States
}

Received 17 May 2005; received in revised form 3 August 2005; accepted 8 September 2005

Available online 4 November 2005

\begin{abstract}
Oliver and Shor [2003, Digital redemption of coupons: Satisfying and dissatisfying effects of promotion codes. Journal of Product and Brand Management 12(2), 121-134] provide data suggesting that Web sites prompting customers to enter a "promotion code", a digital version of the coupon, may unwittingly be losing customers who otherwise would be willing to purchase. They suggest that the act of requesting such a code hints at the existence of price promotions that may be unavailable to the current shopper, potentially diminishing one's likelihood of purchase. We extend their experiment to address the issue of price discrimination and profitability in this context. Our results demonstrate that this diminished likelihood of purchase has adverse effects on profitability and offsets any gains from market segmentation. Further, we analyze a firm's ability to deliver coupons to targeted market segments successfully, given the availability of such coupons on multiple Web sites outside of the retailer's control. We observe that the existence of coupon repositories distorts efficient price discrimination, leading to segmentation of consumers not along dimensions of price sensitivity but of technical competence. These results have managerial implications for those considering online couponing policies. (C) 2005 Elsevier B.V. All rights reserved.
\end{abstract}

JEL classification: L12; M31

PsycINFO classification: 3900

Keywords: Web promotions and coupons; Willingness to pay and consumer behavior; Segmentation and price discrimination

\footnotetext{
* Corresponding author. Tel.: +1 6153434334 .

E-mail addresses: mike.shor@owen.vanderbilt.edu (M. Shor), rloliver@owen.vanderbilt.edu (R.L. Oliver).
} 


\section{Introduction}

Coupons permit a retailer to price discriminate by selling the same good or service to different consumers at varying prices. If a consumer does not provide a coupon at checkout, a retailer is unlikely to mention the existence of a discount. This very prompt could encourage a consumer willing to buy at that moment to delay purchase and seek out the discount, resulting in added stress on customer service call centers and complaint resources (Internet Retailer, 2003), or hint that others may be getting a better deal (Feinberg, Krishna, \& Zhang, 2002; Rich, 2003). By pointing out the existence of price promotions, the very act of prompting for a coupon - a common online practice - may alter a consumer's willingness to complete the purchase.

Further distinguishing online coupons from their traditional paper cousins is the existence of new distribution channels outside of retailers' control. Traditionally, coupons find their way into consumer hands either through targeting of specific customer bases (e.g.,Chen, Narasimhan, \& Zhang, 2001) or through self-selection by placement into newspapers or other outlets (e.g., Moorthy, 1984; Narasimhan, 1984). Web coupon repositories - independent Web sites aimed solely at providing coupon listings - allow anyone to obtain existing discounts. For example, one such site, Flamingo World, touts that its staff "spend several hours each day scouring the internet for these deals so that you don't have to!",

Oliver and Shor (2003) have shown that the traditional web design, whereby consumers are prompted for a coupon code, can have adverse effects on consumer reactions, especially for those not having a code. This prompting requirement in online environments is yet another facet of the effects of web design on many and varied consumer responses (e.g., Drèze \& Zufryden, 1997; Wolfinbarger \& Gilly, 2003). As a result, web managers are faced with a dilemma if they wish to offer discounts to those with lower valuations of their product. On the one hand, the benefits of market segmentation and price discrimination could enhance purchase among consumers needing added incentives and, on the other, the very practice of price discrimination on the web may frustrate those current customers who are less likely to have web coupons. In the context of a behavioral experiment, we seek to estimate the offsetting tendencies of these countervailing effects through the development of an analytic framework.

We address directly the magnitude of the online couponing conundrum in terms of its specific impact on profit. In this paper, we add to the literature in the following manner. First, we analyze purchase probabilities as functions of both the respondents' stated willingness to pay and the experimental condition. This analysis allows us to gauge how sensitive is the link between consumer surplus and purchase intention to our fairness manipulations. Second, we assess the profit implications of incorporating non-neoclassical economic assumptions (fairness in the present case) into the classical model. Lastly, we present the first analysis known to the authors of the motivations behind web coupon search. We consider specifically if acquisition utility (consumer surplus) is subordinate to more practical considerations of web knowledge and technical competence.

\footnotetext{
1 "How to Use Online Coupons," Flamingo World, http://www.flamingoworld.com/help, Web accessed 11/17/ 2004.
} 


\section{Literature}

Conventional economic analysis holds that people base purchasing decisions on consumer surplus, buying if their valuations of an object exceed the price and not buying otherwise. Realistically, such decisions may not be considered independent of the context within which the purchase is made (e.g., Feinberg et al., 2002; Kahneman, Knetsch, \& Thaler, 1986a, Kahneman, Knetsch, \& Thaler, 1986b). Reactions to discount policies, issues of fairness, and other factors may serve to alter consumers' willingness to buy at a given price. For example, posting a "sale" sign on selected items increases demand even without a change in price (Anderson \& Simester, 1998; Inman, McAlister, \& Hoyer, 1990), while price inequity may lower repurchase intentions (Oliver \& Swan, 1989).

Perceived price unfairness significantly alters one's willingness to pay (Ajzen, Rosenthal, \& Brown, 2000; Campbell, 1999; Martins \& Monroe, 1994). In the terminology of Thaler (1985), being prompted for a coupon does not alter the acquisition utility for those without a coupon but may change perceptions of transaction utility, which "measures the perceived value of the "deal" (Thaler, 1999, p. 189) and may be influenced by fairness concerns. The firm's offering of price concessions to a select few might be attributed to the firm acting in its own best interests (Kahneman et al., 1986a, 1986b). Campbell (1999) notes that inferred motives for a firm's use of pricing strategies have not been fully explored and cautions that perceived price unfairness may be firm and context specific.

While traditional analysis of price discrimination holds that a monopolist always benefits from introducing coupons to targeted market segments, the opposite may occur if consumers draw inferences from the very existence of market segmenting policies (Anderson \& Simester, 2001). Coupons not only lower the effective price for some consumers but alter the purchasing context. Consumers may be induced to purchase simply due to their possession of a coupon (Sen \& Johnson, 2000) or how a coupon is presented may impact conversion rates (LeClerc \& Little, 1997). Online, Oliver and Shor (2003) find that the act of prompting for a coupon code impacts consumers in the psychological domain. The authors noted adverse effects of prompting on feelings of equity and satisfaction but left open questions about a retailer's profitability and ability to segment online. We extend their experiment introducing additional variables to address three questions. First, how does prompting for a coupon change a consumer's likelihood of purchase over a range of product valuations? Second, how does this change impact firm profits? Third, how does the existence of coupon repositories transform a firm's ability to target coupons to the most price-sensitive consumers?

In the next section, we develop a model of market segmentation which accounts for behavioral reactions to a firm's pricing policies. In contrast to a traditional rationalist approach, we allow identical consumers to make different purchasing decisions in response to prompting for a coupon code, even when facing the same price. We estimate this model of demand using data from an online behavioral experiment.

\section{Framework and hypotheses}

\subsection{Demand model and profitability}

Ideally, a coupon is used when consumers are separable according to their willingness to pay for a product or service. Consumers with higher willingness to pay face the posted 
price while other consumers receive a coupon and face an effectively lower price. If a person's stated willingness to pay for an object exclusively determines one's purchasing patterns - buy only if this number exceeds the price - then the seller is always benefited by market segmentation. Intuitively, a seller can simply set the same price for each market segment and obtain profits equivalent to those without price discrimination. Since segmentation permits the seller to control more variables in the profit equation (the prices charged in each segment), it cannot be to the seller's detriment to price discriminate.

Fundamentally, analysis of market segmentation relies on the assumption that consumers with a higher willingness to pay are more likely to purchase the product at any given price. While this assumption is rarely in contention, Oliver and Shor (2003) show that consumers without a coupon indicate lower satisfaction and purchase intention when prompted for a code. If consumers without coupons exhibit diminished incentives to purchase, then the resulting loss may negate any benefits of market segmentation, leading to lower profits. Our primary research objective is to compare the profitability of an online retailer who practices price discrimination by prompting for a coupon with one who does not. To this end, subjects were presented with one of two web sites: one prompted consumers to enter a promotion code at checkout while the other did not. Those not prompted for a coupon serve as our control treatment and pay the advertised price. Consumers prompted for a coupon are further subdivided into two classes - those who do not have a coupon and thus pay the regular price and those with a coupon for whom the effective price is lower. We propose a framework for analyzing two-tiered pricing structures when the likelihood of a consumer's purchase may change as a result of the segmentation process itself.

Formally, denote by $q_{t}(w-p)$ the probability of purchase for a consumer with a willingness to pay $w$ when the effective price (net any price reduction) is $p$, with $t$ representing the conditions Have Code - prompted $(H)$, Don't Have Code - prompted $(D)$, and the Control - not prompted $(C)$ treatment in which the retailer does not engage in couponing. For example, $q_{\mathrm{D}}(20)$ is the purchase probability for a consumer who is willing to pay $\$ 20$ more for an item than its price and who does not have a promotion code but is prompted for one. Let $f(w)$ denote the distribution of valuations in the population.

To give market segmentation its best chance of success, we assume an idyllic setting for the retailer. Consider a company which can perfectly segregate consumers into two market segments, low and high, based on whether or not they are willing to pay above some threshold, $w^{*}$. Consumers in the high segment $\left(w>w^{*}\right)$ face a price of $p_{\mathrm{h}}$ while those in the low segment $\left(w<w^{*}\right)$ are issued a coupon and face an effective (post discount) price of $p_{1}$. The neoclassical economic representation of the firm's profit-maximization problem with and without price discrimination may be expressed as: ${ }^{2}$

$$
\begin{array}{ll}
\max _{p_{1}, p_{\mathrm{h}}}\left(p_{1} \sum_{w^{*}>w \geqslant p_{1}} f(w)+p_{\mathrm{h}} \sum_{w \geqslant \max \left(p_{\mathrm{h}}, w^{*}\right)} f(w)\right) & \text { with price discrimination } \\
\max _{p}\left(p \sum_{w \geqslant p} f(w)\right) & \text { without price discrimination }
\end{array}
$$

\footnotetext{
${ }^{2}$ For expositional simplicity, we assume that the costs of production are zero. Incorporation of constant marginal costs would not change qualitatively the results that follow.
} 
In words, the firm selects the price for each market segment which best balances the profit from each transaction with the expected number of consumers willing to pay at least as much as the price. In contrast to the neoclassical approach, we allow the reaction of consumers to a given price to depend upon the company's couponing practices. For example, mere possession of a coupon may induce purchase (Sen \& Johnson, 2000). Alternately, even consumers with high willingness to pay but bereft of a coupon may be less likely to purchase when cognizant of coupons in the hands of other consumers. The following expression derives the profit-maximization problem that arises with and without price discrimination when incorporating these behavioral notions:

$$
\begin{array}{ll}
\max _{p_{1}, p_{\mathrm{h}}}\left(\begin{array}{c}
p_{1} \sum_{w^{*}>w} f(w) q_{\mathrm{H}}\left(w-p_{1}\right) \\
+p_{\mathrm{h}} \sum_{w \geqslant w^{*}} f(w) q_{\mathrm{D}}\left(w-p_{\mathrm{h}}\right)
\end{array}\right) & \text { with price discrimination } \\
\max _{p}\left(p \sum_{w} f(w) q_{C}(w-p)\right) & \text { without price discrimination }
\end{array}
$$

Expected sales are found by summing over all possible values of $w$ the number of people who have that willingness to pay multiplied by their likelihood of purchase. The differences between Eqs. (1) and (2) are twofold. First, traditional profit maximization assumes that consumers will purchase a product whenever $w \geqslant p$ (their willingness to pay exceeds the price) and will never purchase when their willingness to pay is less than price. The behavior-adjusted equation instead recognizes that a stated willingness to pay is only a reference point meaning a purchase is more likely if the price falls below this level, but is not assured (e.g., Grewal, Monroe, \& Krishnan, 1998; Han, Gupta, \& Lehmann, 2001). Similarly, if one's willingness to pay is below the price, some probability of purchase remains. Second, Eq. (2) incorporates treatment effects - two identical consumers facing the same price may have different likelihoods of purchase depending on whether they are prompted for a coupon. We hypothesize, in light of the descriptive results in Oliver and Shor (2003), that the existence of coupon codes will moderate the relationship between one's willingness to pay and the likelihood of purchase.

Hypothesis 1. While likelihood of purchase will be positively correlated with a consumer's willingness to pay for a given object, this relationship will be moderated by the existence of a coupon prompt; the probability of purchase will decrease if those without a coupon code are confronted by a code prompt and increase for consumers in possession of a code over the full range of values of willingness to pay.

The implication is that one's likelihood of purchase at a given price is inexorably linked to the existence of coupon policies. A common rule of thumb is that a firm should offer discounts to consumers who are unwilling to purchase at the posted price. For example, if a product is currently offered at $\$ 20$, providing coupons to consumers with a willingness to pay below $\$ 20$ increases firm profits since additional sales are gained from consumers unwilling to purchase at the original price (Neslin, 1990). However, if consumers who were willing to purchase at the posted price are now less likely to buy due to the introduction of coupons, this policy may fail to increase profits. Coupons in the possession of more pricesensitive consumers may encourage purchase by those who would not ordinarily buy; simultaneously, prompting all consumers for a coupon may depress likelihood of purchase 
by the less price-sensitive but now couponless consumers. In balancing these two effects, we hypothesize that the net impact may be lower profits as a result of market segmentation.

Hypothesis 2. The resulting suppression of likelihood of purchase among couponless consumers may cause the firm to earn lower profits with price discrimination than without price discrimination.

\subsection{Effective targeting}

Lastly, we hypothesize a high correlation between a customer's technical competence and whether the customer finds searching for online coupons to be worth her time. This may negate effective segmentation strategies based on willingness to pay.

Coupons serve as a market segmentation tool. Exogenous distinctions such as age or company affiliation have been used to segment consumers in products as diverse as movie tickets and mortgage accounts (Ladd, 1998). For example, purchase history signals whether a consumer should receive a coupon at checkout (Rossi, McCulloch, \& Allenby, 1996). When observable distinctions do not exist among consumers, firms may provide a menu of options allowing customers to self-select. A Saturday night stay discount allows airlines to distinguish between business travelers, who generally prefer not to stay an extra night, and vacation travelers, who both prefer a weekend stay and are more price-sensitive (Dana, 1998). In short, effective targeting hinges on a retailer's ability to separate consumers by characteristics indicative of their willingness to pay (e.g., Bester \& Petrakis, 1996).

Effective self-selection requires that the costs of search, storage, and use of coupons be large enough to deter use by consumers with high willingness to pay yet small enough to encourage search by consumers with lower willingness to pay. The online world improves searching ability not only from the general workings of the Internet (Alba et al., 1997; Bakos, 1997) but specifically from the existence of coupon repositories independent of the firms whose promotions are advertised. These repositories are updated daily and allow users to add newly discovered promotions. For example, upon being asked to enter a "coupon number" at the Dell computer store Web site, a user may simply enter the words "Dell coupon code" into Google, a popular search engine, and be greeted with nearly one million results, mostly of coupon repositories. ${ }^{3}$ Several such sites provided coupons in the \$100-200 range. Technical expertise on the Web likely provides an advantage to those who are aware of such coupon sites and are adept at Web searches. While consumers with lower willingness to pay are more likely to hunt for traditional paper coupons, we expect online self-selection to occur along lines of technical savvy.

Hypothesis 3. Whether a consumer believes that searching for online coupons is worth his or her time will be highly correlated with technical expertise and less correlated with the consumer's willingness to pay for the product.

\footnotetext{
${ }^{3}$ Google.com Web search 17 November 2004 resulted in a reported 962,000 results.
} 


\section{Method}

\subsection{Survey procedure}

Survey participants were guided through a hypothetical shopping experience. Subjects were informed that they are visiting a fictitious web retailer in search of a specific toy recommended by the mother of a child who will soon be having a birthday party. Subjects were guided through searching for the toy at the site and adding it to their virtual shopping cart. The toy was listed at a price of $\$ 39.99$. The medium was borrowed from Oliver and Shor (2003) though we analyze several additional questions that relate to the focus of this study.

Following the selection of the item, respondents saw a checkout screen modeled after several popular online retailers. The screen contained payment, shipping (included), and price information. This screen contained the stimulus material. The control group saw a summary of the toy's price and no mention of the existence of promotion codes. Remaining participants were prompted to "enter a promotion code". Half of these subjects were without a code and thus "paid" the full price. These subjects were not aware of the magnitude of possible savings. The other half of the subjects were prompted for a promotion code and did have one worth a $\$ 10$ discount, resulting in a final price of \$29.99.

Following checkout, subjects were surveyed on purchase completion likelihood, willingness to pay for an item like the one in the experiment, and propensity to search for coupon codes. A survey given prior to the stimulus materials provided questions for the technical competency scale. All survey components are listed in Appendix A.

Given the minimalist checkout procedure, it is possible that subjects could infer the nature of the experiment. Fifty subjects were randomly polled at the conclusion of the experiment to describe what, if anything, they believed the experiment was about. Most provided replies such as "the effect of web site design", "the role of free shipping", "the speed at which customers shop", and other such incorrect conclusions. Only two subjects noted that they believed promotion codes were central to the study prior to seeing the final survey which asked questions about promotion codes. One of the two listed such codes among six other possible research agendas. It appears that modeling the checkout screen after the most familiar retailers to subjects (it is quite similar to the layout of the checkout screen at Amazon.com, for example) led to little inference about the nature of the experiment.

\subsection{Respondents}

A total of 375 participants were recruited from four primary sources: MBA students at the authors' institution; a list of survey panelists who had previously expressed an interest in participating in research surveys; an advertisement on Google, a leading search engine, seeking participants for a brief survey; and links to the survey placed at a number of web sites. A total of 684 people visited the introductory page for the survey, implying a participation rate of $55 \%$. No significant differences were found between subjects across recruitment methods thus results are reported for pooled data.

Several procedures were used to guard against multiple participation by a single subject. First, students at the authors' institution are required to have a personal laptop, and each is assigned a unique network IP (internet protocol) address. Second, respondents could 
provide a name and email address to be updated on study results, and a majority volunteered this information. Third, IP addresses were tracked to make sure that none was seen twice (none was). Lastly, for robustness, we checked for second-level domain addresses among participants outside of the authors' institution. For example, a user from AOL may be issued a different IP address each time she logs on, but all will have the same second-level domain (e.g., all addresses of the form xxxx.xxxx.aol.com share the aol.com second-level domain). A total of 16 similar second-level domains (six users from aol.com, and five pairs of users from other domains) were identified. While these likely represent different users (10 of the 16 provided names), the analysis was performed dropping these users from the data with no qualitative change in results.

\subsection{Instruments and measures}

The focus of the present study is to measure the impact of prompting on firm segmentation strategy and profitability. To this end, we use the Oliver and Shor (2003) measure of purchase completion but add additional variables to measure willingness to pay, technical competence, and coupon search propensity.

The first survey component acquired respondents' Web experience data. These Web experience items were averaged to form a technical competency scale with a Cronbach's alpha value of 0.76 . Following the hypothetical purchase, subjects faced three other survey components. First, a non-completion item captures "abandonment" tendencies on the part of the respondent and, after an appropriate transformation described later, also serves as a proxy for purchase probability. Second, a question whether subjects find searching for coupon codes worthy of their time solicits respondents' willingness to search for codes. Lastly, an open-ended question soliciting the maximum one would spend for a gift toy provides a measure of a subject's willingness to pay in the context of the present study. All items (except willingness to pay) were recorded on seven-point agree-disagree scales. As noted, all survey items are listed in the appendix. Descriptive statistics and inter-item correlations are presented in Tables 1 and 2. Mean willingness to pay did not differ significantly across treatments ( $p$-values of $0.861,0.920$, and 0.921 in pairwise $t$-tests).

Table 1

Descriptive statistics $(N=375)$

\begin{tabular}{lllllll}
\hline Variable & \multicolumn{7}{l}{ Quartile } & & & \\
\cline { 2 - 7 } & Min & First & Median & Third & Max & Mean (standard deviation) \\
\hline Purchase non-completion & 1 & 3 & 4 & 6 & 7 & $4.05(1.85)$ \\
Search for codes & 1 & 3 & 4 & 6 & 7 & $4.08(1.70)$ \\
Willingness to pay & 5 & 20 & 30 & 40 & 200 & $33.58(22.70)$ \\
Technical competency scale & 1 & 4.75 & 5.5 & 6.25 & 7 & $5.38(1.08)$ \\
Competency & 1 & 5 & 6 & 7 & 7 & $5.92(1.21)$ \\
Effort & 1 & 4 & 5 & 6 & 7 & $5.16(1.41)$ \\
Search & 1 & 5 & 6 & 6 & 7 & $5.39(1.28)$ \\
Frequency & 1 & 4 & 5 & 6 & 7 & $5.05(1.70)$ \\
\hline
\end{tabular}


Table 2

Correlation coefficients $(N=375)$

\begin{tabular}{llrlrlllll}
\hline \multirow{2}{*}{ No. } & Variable & \multicolumn{2}{c}{ Variable } & & & & & \\
\cline { 2 - 9 } & & 1 & 2 & 3 & 4 & 5 & 6 & 7 & 8 \\
\hline 1 & Purchase non-completion & - & 0.05 & -0.24 & 0.03 & 0.03 & -0.05 & 0.07 & 0.04 \\
2 & Search for codes & 0.05 & - & 0.03 & 0.35 & 0.27 & 0.24 & 0.29 & 0.28 \\
3 & Willingness to pay & -0.24 & 0.03 & - & 0.01 & 0.00 & -0.01 & 0.02 & 0.02 \\
4 & Technical competency scale & 0.03 & 0.35 & 0.01 & - & 0.77 & 0.74 & 0.80 & 0.78 \\
5 & Competency & 0.03 & 0.27 & 0.00 & 0.77 & - & 0.51 & 0.56 & 0.41 \\
6 & Effort & -0.05 & 0.24 & -0.01 & 0.74 & 0.51 & - & 0.44 & 0.35 \\
7 & Search & 0.07 & 0.29 & 0.02 & 0.80 & 0.56 & 0.44 & - & 0.51 \\
8 & Frequency & 0.04 & 0.28 & 0.02 & 0.78 & 0.41 & 0.35 & 0.51 & - \\
\hline
\end{tabular}

\section{Results}

\subsection{Stated intent to complete the purchase}

We begin by noting that the very existence of coupon codes has an effect on consumers' reported intentions to complete a purchase. The act of segmenting a market through couponing practices can alter purchase decisions when customers are prompted for coupons. In effect, we confirm the intuition found in the descriptive results on customer satisfaction in Oliver and Shor (2003) and note that this impacts the decision to purchase.

To lend support for Hypothesis 1, we conduct ordered logit analysis to estimate the treatment effects and the role of willingness to pay on the probability of each of the seven responses to the likelihood of non-completion question. Results are presented in Table 3. For ease of interpretation, the scale is reversed so that higher values imply a greater propensity to complete the purchase. First, we note that the coefficient for willingness to pay is positive and highly significant, indicating that it correlates with greater stated intent to complete the purchase. More notable is the significant negative coefficient on the Don't Have Code - prompted dummy variable, indicating a decreased intent to purchase due to the existence of a coupon code field, even when controlling for willingness to pay. The coefficient on the Have Code - prompted dummy variable is positive, but at a much lower significance $(p=0.06)$.

To see how dramatic is this distinction, Fig. 1 shows the estimated cumulative probability of each response at three different levels of consumer surplus. In the top panel, for example, we consider consumers who face an effective price (net of the coupon for those who have them) that is higher by $\$ 10$ than their willingness to pay. We observe that half of these consumers who have a coupon are expected to indicate a "neutral" to "very likely" intent to complete purchase compared to $37 \%$ in the control group. Only $22 \%$ of those without a coupon will indicate similarly, a reduction of 15 percentage points relative to the control group. If we instead consider a consumer with a consumer surplus of $\$ 50$, the likelihood of expressing strong completion intent increases in all treatments, but the same relative ordering remains. While an estimated half of the "couponless" indicate at least neutral tendencies to complete the purchase compared to $71 \%$ in the control group, this rises to over $81 \%$ in the "have coupon" group. The middle panel demonstrates a similar trend when consumer surplus is equal to zero. 
Table 3

Logit estimation for likelihood to complete purchase

\begin{tabular}{|c|c|c|}
\hline \multicolumn{3}{|l|}{ Parameter estimates } \\
\hline & Parameter estimate (error) & Wald chi-square test ( $p$-value) \\
\hline Willingness to pay & $\begin{array}{l}0.0227 * * * \\
(0.0045)\end{array}$ & $\begin{array}{l}25.29 \\
(0.0001)\end{array}$ \\
\hline Have Code - prompted & $\begin{array}{l}0.5049^{*} \\
(0.2708)\end{array}$ & $\begin{array}{l}3.48 \\
(0.0623)\end{array}$ \\
\hline Don't Have Code - prompted & $\begin{array}{l}-0.7527 * * * \\
(0.2721)\end{array}$ & $\begin{array}{l}7.65 \\
(0.0057)\end{array}$ \\
\hline Intercept 1 & $\begin{array}{l}-3.0814^{* * * *} \\
(0.3341)\end{array}$ & $\begin{array}{l}85.05 \\
(0.0001)\end{array}$ \\
\hline Intercept 2 & $\begin{array}{l}-1.8523^{* * *} \\
(0.2947)\end{array}$ & $\begin{array}{l}39.52 \\
(0.0001)\end{array}$ \\
\hline Intercept 3 & $\begin{array}{l}-1.1487 * * * \\
(0.2834)\end{array}$ & $\begin{array}{l}16.43 \\
(0.0001)\end{array}$ \\
\hline Intercept 4 & $\begin{array}{l}-0.2282 \\
(0.2783)\end{array}$ & $\begin{array}{l}0.67 \\
(0.4124)\end{array}$ \\
\hline Intercept 5 & $\begin{array}{l}0.4028 \\
(0.2814)\end{array}$ & $\begin{array}{l}2.05 \\
(0.1523)\end{array}$ \\
\hline Intercept 6 & $\begin{array}{l}1.5453^{* * *} \\
(0.3040)\end{array}$ & $\begin{array}{l}25.84 \\
(0.0001)\end{array}$ \\
\hline
\end{tabular}

Overall model fit

\begin{tabular}{lllll}
\hline Criterion & Without covariates & With covariates & $\chi^{2}$ for covariates & $\operatorname{Pr}>\chi^{2}$ \\
\hline$-2 \log L$ & 1364.413 & 1306.425 & $57.989 * * *$ & $<0.0001$ \\
\hline
\end{tabular}

Significance at $(* * *) 1 \%$ and $(*) 10 \% . N=355$.

The Control - not prompted condition is the baseline.

The scale for the dependent variable is reversed for ease of interpretation.

Specifically, higher values imply greater likelihood of purchase.

\subsection{Estimated likelihood of purchase}

The preceding section implies that those without a coupon are less likely to purchase when prompted for a code. In this section, we estimate the behavioral model of demand (Eq. (2)) to examine the extent to which likelihood of purchase is influenced by the act of prompting for codes. Since we do not observe the probability of purchase directly, we use respondents' stated intent to complete the purchase as a proxy for their purchase probability. For example, a respondent who states strong intent to complete the purchase may be viewed as likely to purchase with probability close to one and one who notes neutrality may be viewed as equally likely to complete or not complete the purchase.

We transform each subject's stated intent into a probability measure and then estimate a logistic model of likelihood of purchase incorporating both consumers' willingness to pay and treatment effects. Letting $r$ denote the response on our seven-point scale 

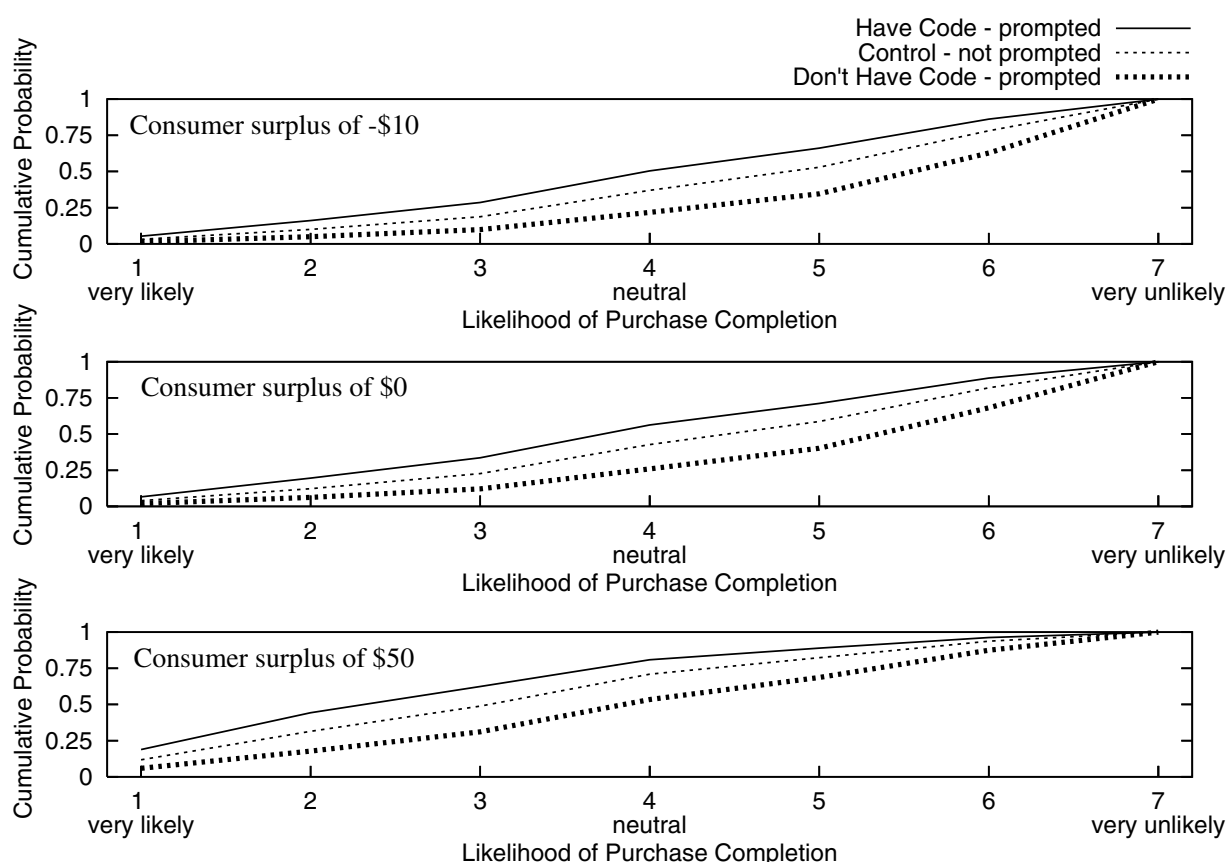

Fig. 1. Estimated cumulative distribution of reported purchase likelihood at three levels of consumer surplus. Higher lines imply greater likelihood.

( 7 = strongly agree that he or she would not complete the purchase), we let the probability of completing a purchase by a subject in treatment $t$ be given by

$$
q_{t} \equiv \operatorname{Pr}\{\text { completion }\}=\alpha+(1-2 \alpha) \frac{7-r}{6}
$$

Hence, we transform survey responses into probabilities evenly spaced on the interval $[\alpha, 1-\alpha]^{4}$ Next, letting $p$ denote the effective price (incorporating the reduction, if any), we posit a logistic model of the effects of a consumer's willingness to pay on the likelihood of purchase, by treatment:

$$
\ln \left(\frac{q_{t}}{1-q_{t}}\right)=\beta_{0}+\beta_{1}(w-p)
$$

Table 4 presents the results of the regression. ${ }^{5}$

\footnotetext{
${ }^{4}$ Results from alternate, non-linear transformations are presented in Appendix B.

${ }^{5}$ To check for undue leverage of any group of data points, regressions were also run after dropping observations based on several specifications of extremal values without any change to the significance of the results. The transformation given by Eqs. (3) and (4) is equivalent to the empirical logistic transformation (Cox, 1970). Estimates were also obtained using OLS, probit, and the linear probability model using weighted least squares to overcome heteroscedasticity. All models gave the same qualitative results in terms of the ordering of parameters, but all but the logit and probit share the unsatisfactory feature of predicted probabilities outside of the $[0,1]$ range. For what follows, we assume that $\alpha$ is small $\left(10^{-6}\right)$ but the reported parameter ordering is preserved for all values.
} 
Table 4

Regression results for probability of purchase completion by treatment

\begin{tabular}{lcc}
\hline Treatment & Intercept (error) & Consumer surplus $(w-p)($ error $)$ \\
\hline Have Code - prompted & $1.454^{* * *}$ & $0.053^{* * *}$ \\
$(N=150)$ & $(0.471)$ & $(0.019)$ \\
Control - not prompted & 0.119 & $0.066^{* * *}$ \\
$(N=75)$ & $(0.066)$ & $(0.027)$ \\
Don't Have Code - prompted & $-1.583^{* * *}$ & $0.085^{* * *}$ \\
$(N=150)$ & $(0.576)$ & $(0.025)$ \\
\hline
\end{tabular}

Significance at $(* * *) 1 \%$, unstandardized coefficients.

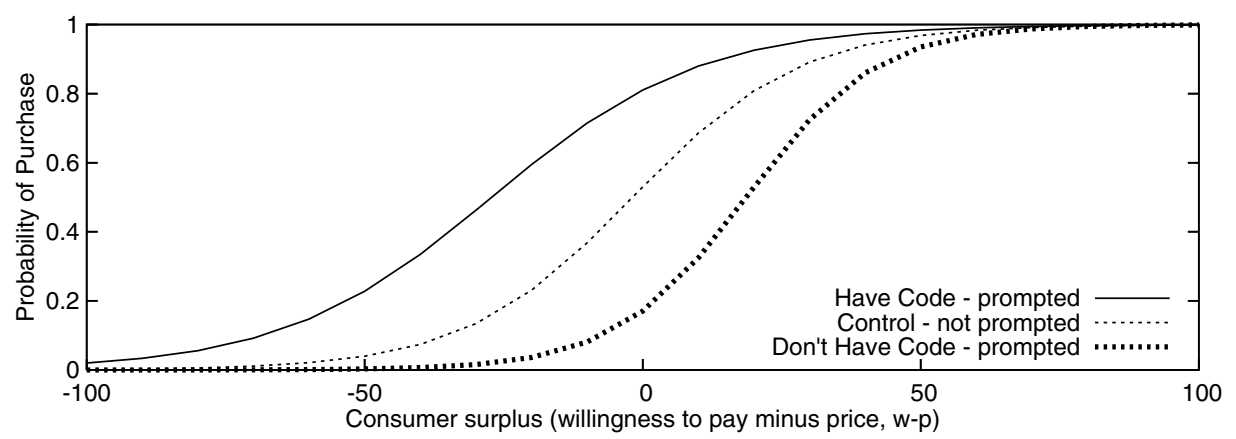

Fig. 2. Estimated probability of purchase completion by treatment (using estimated parameters from Table 4).

Notably, the intercept for the Don't Have Code - prompted treatment is negative, the intercept for the Have Code-prompted treatment is positive, while the Control treatment intercept is not significantly different from zero, reflecting downward adjustment in the probability of purchase due to being prompted and not having a code. Fig. 2 illustrates these predicted probabilities as a function of consumer surplus.

For sufficiently high prices (low values of $w-p$ ), all consumers are unlikely to purchase. Those with exceptionally high willingness to pay are likely to purchase independent of a retailer's couponing policies. In the middle range, where most consumers lie, the three treatments are clearly ordered. Consumers with a code have the highest probability of purchase, followed by the control group, and finally by those without a code but prompted for one. To fix ideas, consider a consumer who faces a price equal to his or her stated willingness to pay $(w-p=0)$. This consumer's probability of purchase is $81 \%$ if she is in the Have Code group, $55 \%$ if in the Control group, but only $18 \%$ if in the Don't Have Code group. In support of Hypothesis 1, consumer reaction to a given price appears to be treatment-specific.

\subsection{Profit implications}

The couponless consumer appears less likely to purchase at a given price when confronted by a code prompt. We hypothesized that lower likelihood of purchase among couponless consumers when confronted by a code prompt may cause the firm to earn lower profits with price discrimination than without price discrimination. Below, we test 
this hypothesis using our behavior-adjusted model of demand and find that unless a sizeable majority of consumers are in possession of a coupon, profits do suffer.

For price discrimination to be effective, a firm needs to segment consumers by their willingness to pay and deliver coupons to those who are unlikely to buy without them. In both the neoclassical and behavior-adjusted specifications of profit, (1) and (2), the profit earned depends on the segmentation point, $w^{*}$. A very low segmentation point like $\$ 5$ would imply that most consumers would pay the (optimal) high price, while consumers with very low willingness to pay (below \$5) would receive a coupon for an (optimal) discount. A segmentation point of $\$ 100$, on the other hand, would mean that most consumers would receive a coupon, with the exception of the few with willingness to pay above $\$ 100$.

To test our second hypothesis, both equations were considered for a range of segmentation points, $w^{*}$ (Fig. 3). In the first case, optimal prices with and without segmentation were computed using Eq. (1). Case I ignores the framing effects of price discrimination on altering quantity demanded. The heavy solid line in Fig. 3 represents the profit with market segmentation relative to the profit without any segmentation. In Case II, the amount demanded with and without price discrimination was obtained from the behavior-adjusted Eq. (2). In both cases, relative profit greater than one implies that price discrimination is advantageous for the seller.

Relative profits for Case I are always above one, reflecting the neoclassical economic view that market segmentation always increases profits. However, in Case II, the profitability of price discrimination varies with the point at which consumers are segmented. If segmentation occurs at a relatively low point, additional purchases by the few customers with coupons does not offset the loss of sales from the majority of consumers who do not have a coupon but are now prompted for one. Conversely, for higher segmentation points, the mass of consumers more likely to purchase due to coupon possession dominates the loss of a few consumers without coupons. The behavior-adjusted relative profit line crosses one at $\$ 30$. If market segmentation occurs at less than $\$ 30$, price discrimination is not desirable. Less than $40 \%$ of respondents reported a willingness to pay higher than $\$ 30$, implying that coupons would need to be distributed to at least the bottom $60 \%$. Thus, unless a sizeable majority of consumers are in possession of a coupon, profits suffer.

This analysis is unidirectional. If consumers cannot be reliably segmented at a point above $\$ 30$, then price discrimination is not advisable; however, the converse is not necessarily true. The analysis presupposes perfect segmentation (no consumers with high willingness to pay receiving coupons, for instance), optimal price setting for both market

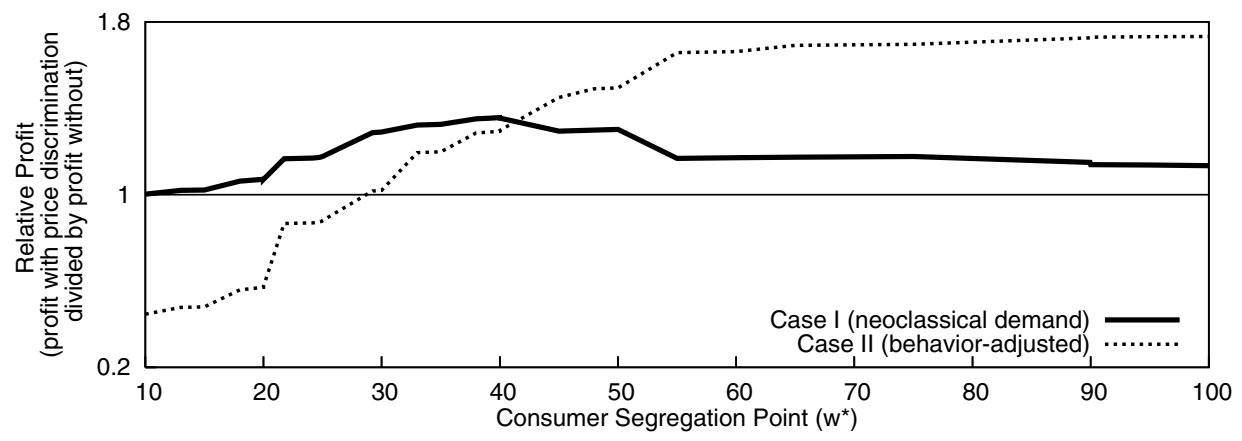

Fig. 3. Relative profit with and without price discrimination. 
segments, and the prevention of resale among consumers. The ability of firms to implement this near-perfect segmentation is analyzed next.

\subsection{Effective targeting}

Can segmentation of customers by willingness to pay occur online? Even consumers not targeted for coupon delivery occasionally obtain them from local distribution systems or from more fortunate friends. While such coupon sharing is relatively rare in the offline world, online, promotion code-oriented Web sites prevail. In this study, respondents were asked to state their agreement with the statement: "It is worth my time to search the Web for promotion, coupon, or discount codes". If segmentation is to be effective, the answer should be negatively correlated with the respondent's willingness to pay for an object. Yet, the "cost" of searching for online coupons may be highly correlated not with one's value for time but with one's technical expertise, since the more tech-savvy may be able to find and use such coupons with greater efficiency than the uninitiated.

We regressed participants' likelihood to search for coupons online on both willingness to pay and technical competency (Table 5). The goodness of fit test suggests that the analysis is highly significant. Whether a consumer finds it worthwhile to search for an online coupon code is driven by technical experience and not willingness to pay. Hence, coupons are likely to find their way into the hands of the more tech-savvy in accord with Hypothesis 3. Much like a price-sensitive segment of the population regularly scours the Sunday paper for coupons prior to its weekly grocery store outing, a tech-savvy segment of the population might search online for coupons whenever prompted for a promotion code. If technical ability correlates positively with socioeconomic status (Hoffman et al., 1998), those most likely to search for coupons are the ones firms would least want to possess them.

This conclusion is not altered by the potentially confounding treatment effects. For robustness, similar analysis was performed stratified by treatment (Table 6). In each treatment, willingness to pay is similarly insignificant at any generally accepted level while technical competence remains conclusively significant.

Table 5

Is searching for coupon codes "worth my time"? Regression results

\begin{tabular}{lll}
\hline Variable & Estimate & $t, p$-value \\
\hline Technical competency & $0.5566^{* * *}$ & $t=7.279, p<0.001$ \\
Willingness to pay & 0.0016 & $t=0.444, p=0.329$ \\
\hline
\end{tabular}

Significance at $\left({ }^{* * *}\right) 1 \% . N=375$. Goodness of fit $F=26.63, p<0.001$.

Table 6

Is searching for coupon codes "worth my time"? Regression results by treatment

\begin{tabular}{llll}
\hline Variable & Have Code $(N=150)$ & Don't Have Code $(N=150)$ & Control $(N=75)$ \\
\hline Technical competency & 0.4422 & 0.6992 & 0.4516 \\
$t$-stat & $t=3.612$ & $t=5.994$ & $t=2.557$ \\
$p$-value & $p<0.001$ & $p<0.001$ & $p=0.006$ \\
Willingness to pay & 0.0054 & -0.0044 & 0.0053 \\
$t$-stat & $t=0.988$ & $t=0.729$ & $t=0.652$ \\
$p$-value & $p=0.162$ & $p=0.234$ & $p=0.258$ \\
\hline
\end{tabular}




\section{Discussion}

Consumers with lower willingness to pay for a product or service may be enticed to purchase a product without sacrificing sales from other consumers through the use of targeted coupons. Such is the maxim of value-based market segmentation which may fail in the digital world. Consumers' likelihood of purchase at a given price is inexorably linked to the existence of coupon policies.

We hypothesized that online coupon prompts would distort the role of willingness to pay as a primary determinant of purchase probability. While willingness to pay remained significant in the purchase intent formula, couponless consumers appeared less intent on completing the purchase when confronted by a code prompt compared to a control treatment which was not prompted for a code. Thus, code prompting may contribute to the widespread phenomenon of abandonment of virtual shopping carts (e.g., BizRate.com, 2000). The extent of consumer reaction likely depends on both the perceived value of possible discounts and the inferred motives for the firm's segmentation strategy (Campbell, 1999). Explorations into these issues may be a fruitful direction for future research.

By diminishing the likelihood of purchase, online couponing calls into question the profitability of online market segmentation. In fact, we find that the reduced likelihood of purchase by the couponless negates any gain from market segmentation unless coupons are targeted towards a large majority of shoppers. Instead, it may behoove retailers to make code prompting a less conspicuous part of the checkout experience. In offline stores, patrons are rarely asked if they "have any coupons", outside of grocery stores. Oliver and Shor (2003) have proposed that online retailers may institute an analogous "back-door" policy for savvy, previous, or experienced shoppers. These individuals would be offered the discount while shoppers entering through the "front-door" would not be exposed to the code prompt. Currently, few major online retailers adopt this policy.

Even if the use of coupons was made more surreptitious, effective targeting of coupons is more challenging in the digital world. It has long been observed that online shoppers are not evenly distributed across the population. Specifically, younger, more educated consumers appear to be more technologically proficient on computer-related devices. Because a computer is necessitated in online shopping, these same skills may give "techies" a major advantage in obtaining online coupons regardless of their price sensitivity. Our research bears this out as expertise dominates willingness to pay in the likelihood of obtaining coupons outside of retailer-controlled channels.

This finding is somewhat different than, but consistent with, several recent papers. Johnson, Moe, Fader, Bellman, and Lohse (2004) find that more active online shoppers tend to search more web sites, thereby exerting more effort in similar fashion, though their data indicate that experience is not a factor in propensity to comparison shop. Hann and Terwiesch (2003) show that Web experience is negatively correlated with "frictional cost" or the disutility of bidding online. The authors discover that demographic factors (perhaps predictors of willingness to pay) are not indicative of willingness to suffer these costs but experience is. As noted, we find that search propensity ("it is worth my time") is highly correlated with technical savvy, presumably through more frequent Web usage.

We have investigated how ignoring the reaction of couponless consumers to being prompted for a code may lead to the counterintuitive result that price discrimination reduces profit. A myriad of psychological factors, including expectation dimensions, anticipated regret, cognitive dissonance, salience of price, and fears of quality lapses 
and subsequent returns all loom as potential deterrents to online purchasing and may promote shopping cart abandonment. Clearly, more work along these lines is needed.

\section{Acknowledgement}

The authors would like to thank Bruce Cooil, Donna Hoffman, Tom Novak, seminar participants at the INFORMS Conference on Pricing Research and Fordham University Pricing Conference, and two anonymous referees, for insightful comments on an earlier draft of this manuscript.

\section{Appendix A. Survey instrument}

Technical competency scale: Four components were presented on a seven-point (disagree-agree) scale.

- Competency: I feel that I am technically competent on the Web.

- Effort: Shopping on the Web is effortless for me.

- Search: I am exceptionally good at searching for things on the Web.

- Frequency: I frequently shop online.

Purchase non-completion intention: The question was presented on a seven-point (disagree-agree) scale.

- If this was a real shopping experience, I would not have completed this purchase.

Search for codes: The question was presented on a seven-point (disagree-agree) scale.

- It is worth my time to search the Web for promotion, coupon, or discount codes.

Willingness to pay: The question was open-ended, allowing the entry of any value.

- If attending a friend's daughter's birthday party, the maximum I would likely spend on a present is:

\section{Appendix B. Alternate transformations of $q_{t}$}

In this section, we evaluate the robustness of the transformation from intent to purchase to probability of purchase. Two alternate transformations are provided (Tables

Table B.1

Regression results for probability of purchase completion under transformation (B.1)

\begin{tabular}{lcc}
\hline Treatment & Intercept (error) & Consumer surplus $(w-p)($ error $)$ \\
\hline Have Code - prompted $(N=150)$ & $-0.612^{* * *}$ & $0.022^{* * *}$ \\
Control - not prompted $(N=75)$ & $(0.220)$ & $(0.009)$ \\
& $-1.281^{* * *}$ & $0.039^{* * *}$ \\
Don't Have Code - prompted $(N=150)$ & $(0.340)$ & $(0.150)$ \\
& $-2.472^{* * *}$ & $0.050^{* * *}$ \\
\hline
\end{tabular}

Significance at $(* * *) 1 \%$, unstandardized coefficients. $\alpha=0.01$. 
Table B.2

Regression results for probability of purchase completion under transformation (B.2)

\begin{tabular}{lcc}
\hline Treatment & Intercept (error) & Consumer surplus $(w-p)$ (error) \\
\hline Have Code - prompted $(N=150)$ & $1.518^{* * *}$ & $0.018^{* * *}$ \\
& $(0.147)$ & $(0.006)$ \\
Control - not prompted $(N=75)$ & $1.100^{* * *}$ & $0.022^{* * *}$ \\
& $(0.188)$ & $(0.008)$ \\
Don't Have Code - prompted $(N=150)$ & $0.565^{* * *}$ & $0.023^{* * *}$ \\
& $(0.158)$ & $(0.007)$ \\
\hline
\end{tabular}

Significance at $\left({ }^{* * *}\right) 1 \%$, unstandardized coefficients. $\alpha=0.01$.

B.1 and B.2); the first diminishes probability of purchase and the second enhances it. In both cases, the qualitative results and ordering of the intercepts obtain.

$$
\begin{aligned}
& q_{t} \equiv \operatorname{Pr}\{\text { completion }\}=\left[\alpha+(1-2 \alpha) \frac{7-r}{6}\right]^{2} \\
& q_{t} \equiv \operatorname{Pr}\{\text { completion }\}=\left[\alpha+(1-2 \alpha) \frac{7-r}{6}\right]^{1 / 2}
\end{aligned}
$$

\section{References}

Ajzen, I., Rosenthal, L. H., \& Brown, T. C. (2000). Effects of perceived fairness on willingness to pay. Journal of Applied Social Psychology, 30(12), 2439-2450.

Alba, J., Lynch, J., Weitz, B., Janiszewski, C., Lutz, R., Sawyer, A., \& Wood, S. (1997). Interactive home shopping: Consumer, retailer, and manufacturer incentives to participate in electronic marketplaces. Journal of Marketing, 61(3), 38-53.

Anderson, E. T., \& Simester, D. I. (1998). The role of sale signs. Marketing Science, 17(2), $139-155$.

Anderson, E. T., \& Simester, D. I. (2001). Price discrimination as an adverse signal: Why an offer to spread payments may hurt demand? Marketing Science, 20(3), 315-327.

Bakos, J. Y. (1997). Reducing buyer search costs: Implications for electronic marketplaces. Management Science, 43(12), 1676-1692.

Bester, H., \& Petrakis, E. (1996). Coupons and oligopolistic price discrimination. International Journal of Industrial Organization, 14(2), 227-242.

BizRate.com, 2000. 78\% of online buyers abandon shopping carts according to bizrate.com survey. BizRate Press Release, 23 October 2000. Available from: <http://bizrate.com/content/press/release.xpml?rel=88>, Web accessed 1 May 2002.

Campbell, M. C. (1999). Perceptions of price unfairness: Antecedents and consequences. Journal of Marketing Research, 36(2), 187-199.

Chen, Y., Narasimhan, C., \& Zhang, J. Z. (2001). Individual marketing with imperfect targetability. Marketing Science, 20(1), 23-41.

Cox, D. R. (1970). The analysis of binary data. London: Methuen.

Dana, J. D. Jr., (1998). Advance-purchase discounts and price discrimination in competitive markets. Journal of Political Economy, 106(2), 395-422.

Drèze, X., \& Zufryden, F. (1997). Testing web site design and promotional content. Journal of Advertising Research, 37(2), 77-91.

Feinberg, F. M., Krishna, A., \& Zhang, Z. J. (2002). Do we care what others get? A behaviorist approach to targeted promotions. Journal of Marketing Research, 39(3), 277-291.

Grewal, D., Monroe, K. B., \& Krishnan, R. (1998). The effects of price-comparison advertising on buyers' perceptions of acquisition value, transaction value, and behavioral intentions. Journal of Marketing, 62(2), 46-59. 
Han, S., Gupta, S., \& Lehmann, D. R. (2001). Consumer price sensitivity and price thresholds. Journal of Retailing, 77(4), 435-456.

Hann, I.-H., \& Terwiesch, C. (2003). Measuring the frictional costs of online transactions: The case of a nameyour-own-price channel. Management Science, 49(11), 1563-1579.

Hoffman, D. L., \& Novak, T. P. (1998). Bridging the racial divide on the internet. Science, 280(5362), 390-391.

Inman, J. J., McAlister, L., \& Hoyer, W. D. (1990). Promotion signal: Proxy for a price cut? Journal of Consumer Research, 17(1), 74-81.

Internet Retailer, 1 October 2003. Online coupons have a role - but not long term, says ebags. Internet Retailer. Available from: <http://www.internetretailer.com/dailyNews.asp?id=10335>, Web accessed 19 July 2005, pp. 187-199.

Johnson, E. J., Moe, W. W., Fader, P. S., Bellman, S., \& Lohse, G. L. (2004). On the depth and dynamics of online search behavior. Management Science, 50(3), 299-308.

Kahneman, D., Knetsch, J. L., \& Thaler, R. (1986a). Fairness and the assumptions of economics. Journal of Business, 59(4), 285-300.

Kahneman, D., Knetsch, J. L., \& Thaler, R. (1986b). Fairness as a constraint on profit seeking: Entitlements in the market. American Economic Review, 76(4), 728-741.

Ladd, H. F. (1998). Evidence on discrimination in mortgage lending. Journal of Economic Perspectives, 12(2), $41-62$.

LeClerc, F., \& Little, J. D. C. (1997). Can advertising copy make fsi coupons more effective? Journal of Marketing Research, 34(4), 473-484.

Martins, M., \& Monroe, K. B. (1994). Perceived price fairness: A new look at an old concept. In C. T. Allen \& D. R. John (Eds.). Advances in Consumer Research (Vol. 21, pp. 75-78). Provo, UT: Association for Consumer Research.

Moorthy, K. S. (1984). Market segmentation, self selection, and product line design. Marketing Science, 3(4), 288-307.

Narasimhan, C. (1984). A price discrimination theory of coupons. Marketing Science, 3(2), 128-147.

Neslin, S. A. (1990). A market response model for coupon promotions. Marketing Science, 9(9), 125-145.

Oliver, R. L., \& Shor, M. (2003). Digital redemption of coupons: Satisfying and dissatisfying effects of promotion codes. Journal of Product and Brand Management, 12(2), 121-134.

Oliver, R. L., \& Swan, J. E. (1989). Equity and disconfirmation perceptions as influences on merchant and product satisfaction. Journal of Consumer Research, 16(3), 372-383.

Rich, D. A., 2003. The 10 most damaging things to say to a customer. In SOCAP Update. Vol. July/August. Society of Consumer Affairs Professionals in Business (pp. 7-8).

Rossi, P. E., McCulloch, R. E., \& Allenby, G. M. (1996). The value of purchase history data in target marketing. Journal of Marketing Research, 15(4), 321-340.

Sen, S., \& Johnson, E. J. (2000). Mere-possession effects without possession in consumer choice. Journal of Consumer Research, 24(1), 515-534.

Thaler, R. H. (1985). Mental accounting and consumer choice. Marketing Science, 4(3), 199-214.

Thaler, R. H. (1999). Mental accounting matters. Journal of Behavioral Decision Making, 12(3), 183-206.

Wolfinbarger, M., \& Gilly, M. C. (2003). etailq: Dimensionalizing, measuring and predicting etail quality. Journal of Retailing, 79(3), 183-198. 